Special issue of the 3rd International Conference on Computational and Experimental Science and Engineering (ICCESEN 2016)

\title{
Scaled Soil-Structure Interaction Model for Shaking Table Testing
}

\author{
F. GoKtere ${ }^{a *}$, A.J. Omid ${ }^{b}$ And E. Celebi ${ }^{b}$ \\ ${ }^{a}$ Bartin University, Department of Civil Engineering, Bartin, Turkey \\ ${ }^{b}$ Sakarya University, Department of Civil Engineering, Sakarya, Turkey
}

\begin{abstract}
The primarily goal of this study is to reveal a scaled soil-structure interaction model for small capacity shaking table testing instead of the full-scale field experiments. The prototype of soil-structure interaction system with frame-type building, resting on a sandy soil with shear wave velocity of $536 \mathrm{~m} / \mathrm{s}$ and unit weight of $12.9 \mathrm{kN} / \mathrm{m}^{3}$ has been selected. For experimental investigations, the realistic site and building structures are scaled with a geometric scaling factor of 1:45. The test model, consisting of six-story steel frame-type building, natural soil and laminar soil container, is designed and constructed to realistically simulate the seismic soil-structure interaction effects of building structures in shaking table tests. In order to verify the geometric scaling factor, the dynamic properties of the fixed-base system for both prototype and scaled model are determined by using finite element analysis. Furthermore, the dynamic parameters for scaled model of a single layer soil, restricted with base-rock, have been compared numerically with the proposed laminar soil container, to provide a good agreement.
\end{abstract}

DOI: 10.12693/APhysPolA.132.588

PACS/topics: Soil-structure interaction, shaking table, finite element analysis

\section{Introduction}

In the recent decades, the problem of soil-structure interaction (SSI) in the seismic analysis and design of structures has become more important [1]. Many experimental, numerical and theoretical methods have been applied in the research of soil-structure interactions [2]. Shaking table test has been increasingly used to study the dynamic responses of different structures under the influence of SSI.

Tabatabaiefar et al. [3, 4] investigated structural behaviour of building structures under the influence of SSI. Li et al. [5] conducted shaking table test of a 1:20 scaled model of a typical reinforced concrete $(\mathrm{RC})$ residential building in Hong Kong. Ko and Lee [6] performed a series of shaking table tests of a 1:12 scale model to investigate the seismic performance of a 17-story $\mathrm{RC}$ high-rise structure. Chunyu et al. [7] performed a series of shaking table tests of a 1:40 scale model, to investigate the seismic performance of Shanghai Tower structure. In this study, scaled soil-structure model for small shaking table test was developed numerically to estimate the earthquake effects on the dynamic response of structures.

\section{Description of prototype}

The prototype of the experimental tests is a soilstructure system with dimensional characteristics illustrated in Fig. 1. The prototype frame-type building of the soil-structure system is six story reinforced concrete building. The height and width of building frame are

*corresponding author; e-mail: fgoktepe@bartin.edu.tr
30 meters and 6 meters, respectively and spacing between the frames is 3 meters. The natural frequency of prototype is $1.348 \mathrm{~Hz}$ and the total mass is 488 tones.

Soil underneath of the structure is sandy soil with the shear wave velocity of $536 \mathrm{~m} / \mathrm{s}$ and the density of soil is $12.9 \mathrm{kN} / \mathrm{m}^{3}$. The length and width of the soil lateral boundaries and bedrock depth have been selected to be 30 meters, 18 meters and 10 meters, respectively.

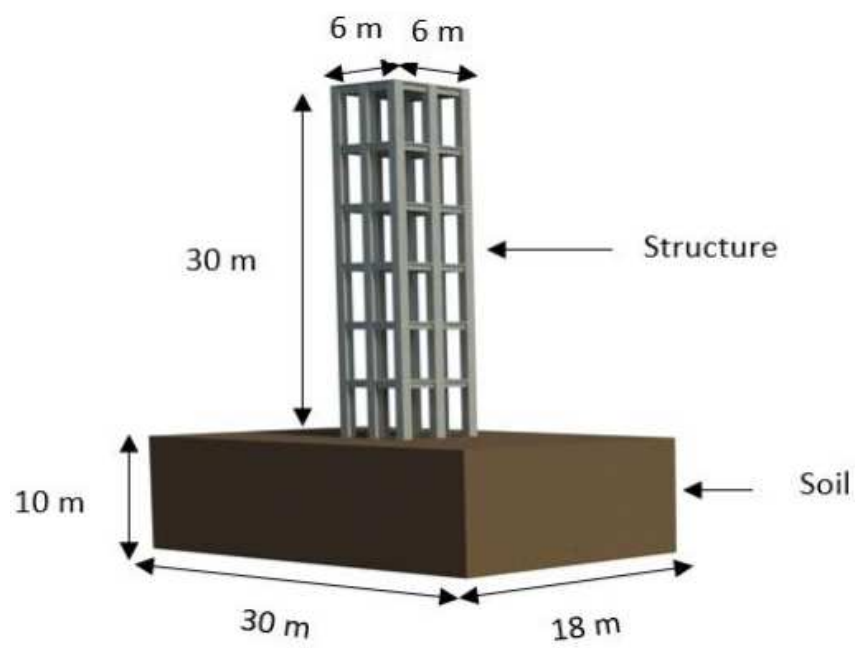

Fig. 1. 3D prototype building of the soil-structure.

\section{Geometric scaling factor and structural model design}

Adopting an appropriate geometric scaling factor $\lambda$, is one of the important steps in scale modelling of shaking table test [3]. The specifications of Sakarya University shaking test table are shown in Table I. In this study, 
the geometric scaling factor of 1:45 was adopted for experimental tests. The height, length and width of the proposed structural model are determined to be $0.66 \mathrm{~m}$, $0.13 \mathrm{~m}$ and $0.13 \mathrm{~m}$, respectively. The considered structure prototype was scaled into a steel structure model, by scaling the natural frequency and density of the real structure. According to scaling factor the relationship between natural frequency of model and natural frequency of proposed structure is:

$$
\frac{f_{\mathrm{p}}}{f_{\mathrm{m}}}=\lambda^{-1 / 2} \text {. }
$$

The density of the prototype $\rho_{\mathrm{p}}$ should be equal to the density of the model $\rho_{\mathrm{m}}$, and the mass of the structural model can be estimated from Eq. (2):

$$
\rho_{\mathrm{p}}=\frac{m_{\mathrm{p}}}{v_{\mathrm{p}}} .
$$

TABLE I

Characteristics of SAU shaking table.

\begin{tabular}{c|c|c|c}
\hline \hline Size of the table & $1 \times 1 \mathrm{~m}^{2}$ & Max. loading weight & $100 \mathrm{~kg}$ \\
Max. payload & $2.5 \mathrm{kN}$ & Max. acceleration & $2 g$ \\
Max. displacement & $\pm 100 \mathrm{~mm}$ & Testing frequency & $1-10 \mathrm{~Hz}$
\end{tabular}

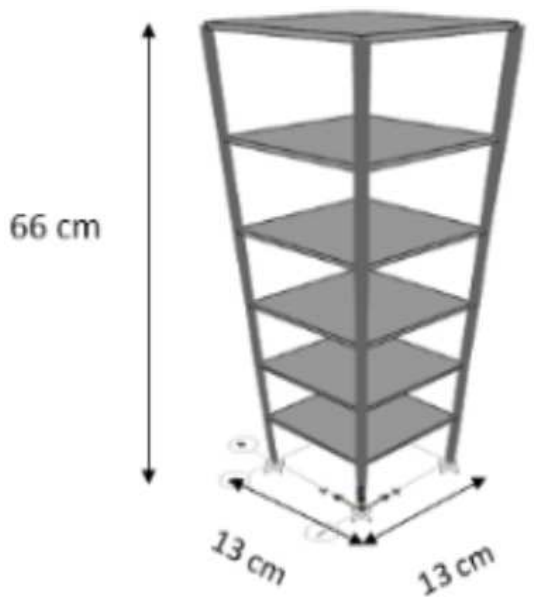

Fig. 2. 3D numerical model of the structure.

The natural frequency of structural model was obtained by using 3D numerical model in SAP2000 software. The 3D model is shown in Fig. 2. The numerical test model consists of six horizontal steel plates, representing the floors, and four vertical plates, representing the columns. The dimensions of the steel plates and columns for the test model are $0.13 \times 0.13 \times 0.06 \mathrm{~m}^{3}$, and $0.66 \times 0.1 \times 0.02 \mathrm{~m}^{3}$ respectively. The mass of the model structure without base plate is $5 \mathrm{~kg}$.

\section{Scaling of earthquake ground motion}

Three earthquake ground motions, including Chi-Chi (1999), Kobe (1995) and Kocaeli (1999), have been adopted for shaking table tests. Accelerations of model remain the same, as the prototype and the time of earthquake ground motion were scaled by factor of 6.7. Displacements of each floors for real structure and test model are obtained in SAP2000 software. After scaling the obtained floor displacements of the real structure, the results agreed with the test model. The comparison graph of response spectrum is shown in the Fig. 3.

\section{Response spectrum}

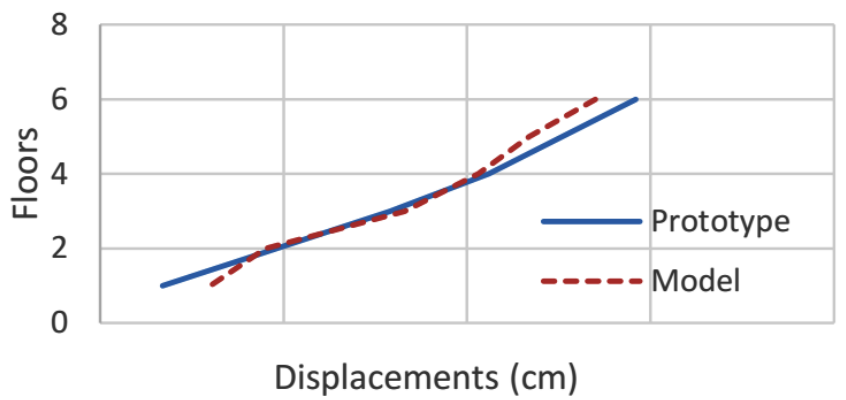

Fig. 3. Comparison of prototype and model.

\section{Adopted laminar soil container}

The laminar soil container is made of aluminium hallow section and flexible rubber. Laminar soil container was scaled by geometric scale factor of $1: 45$ and the dimensions of container were estimated to be $0.7 \mathrm{~m}, 0.45 \mathrm{~m}$ and $0.225 \mathrm{~m}$. According to scaling, the ratio between the shear wave velocity of the soil model $V_{\mathrm{sp}}$ and the shear wave velocity of the prototype soil $V_{\mathrm{sm}}$ can be expressed using Eq. (3):

$$
\frac{V_{\mathrm{sp}}}{V_{\mathrm{sm}}}=\sqrt{\lambda}
$$

Taking into account the shear wave velocity of the prototype soil $V_{\mathrm{sp}}$ of $536 \mathrm{~m} / \mathrm{s}$ and scaling factor, the shear wave velocity of the soil model $V_{\mathrm{sm}}$ is $80 \mathrm{~m} / \mathrm{s}$. The natural frequency of laminar soil container was measured to be $90.9 \mathrm{~Hz}$ in SAP2000. In this case it is equal to the required natural frequency of a single layer soil. The model of laminar soil container is shown in the Fig. 4. The experimental test model of SSI problem is given in Fig. 5.

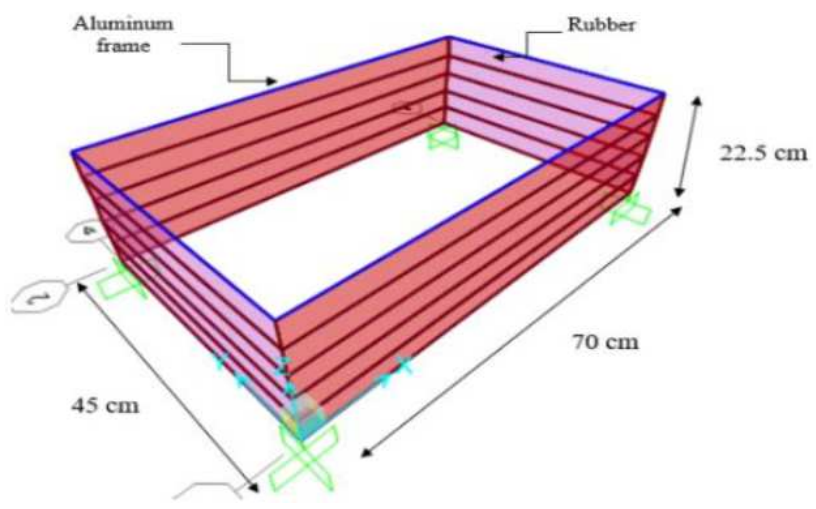

Fig. 4. 3D model of laminar soil container. 


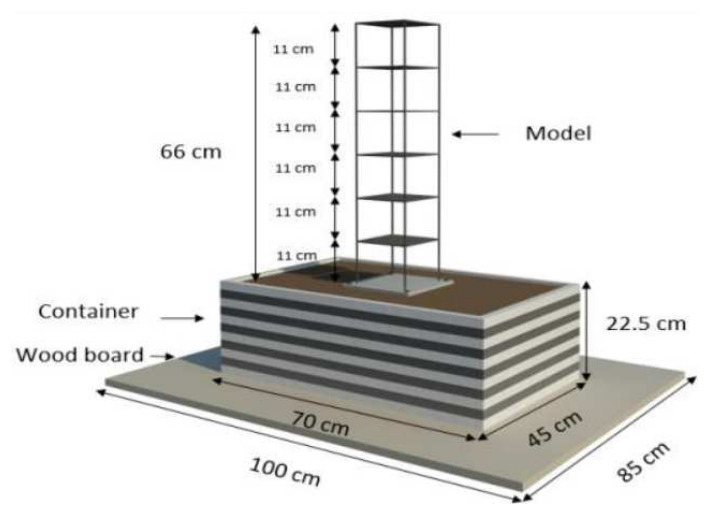

Fig. 5. 3D model of soil-structure interaction.

\section{Conclusions}

The geometric scaling factors were used for scaled SSI model of small capacity shaking table testing, instead of the full-scale field experiments. Before the experiment on shaking table, a series of steps were used to compare the prototype structure with the test model structure, to provide a good agreement. Prototype structure can be modelled more accurately for experimental tests. It is concluded that the proposed numerical soil-structure model is a valid and qualified method of simulation for numerical investigations of dynamic soil-structure interactions.

\section{References}

[1] A. Daamouche, D. Fares, I. Maalem, K. Zemmouri, Acta Phys. Pol. A 130, 28 (2016).

[2] B. Nagy, Acta Phys. Pol. A 128, B-164 (2015).

[3] S.H.R. Tabatabaiefar, B. Fatahi, B. Samali, $A d v$. Struct. Engin. 17, 109 (2014).

[4] H.R. Tabatabaiefar, International Journal 10, 1 (2016).

[5] L. Cs, L. Se, Z. Mz, W. Yl, J. Struct. Engin. 11, 1732 (2006).

[6] D.-W. Koo, H.S. Lee, Earthquake Engin. Struct. Dynam. 35, 1425 (2006).

[7] T.C. Xiao, C. Jinzhe, Int. J. High-Rise Build. 1, 221 (2012). 